\title{
Media Pembelajaran Puzzle pada Bangun Datar Jajargenjang untuk Anak Tunarungu
}

\author{
Vina Septiyani ${ }^{*}{ }^{*}$, Hartatiana ${ }^{2}$, dan Ambarsari Kusuma Wardani ${ }^{3}$
}

Program Studi Pendidikan Matematika, FITK, Universitas Islam Negeri Raden Fatah Palembang Jalan. Prof. K.H Zainal Abidin Fikri, Palembang, Sumatera Selatan, Indonesia.

1*vinasepti19@gmail.com; ${ }^{2}$ hartatiana_uin@radenfatah.ac.id; 3ambarsariks_uin@radenfatah.ac.id ${ }^{3}$

Artikel diterima: 11-09-2020, direvisi: 28-01-2021, diterbitkan: 31-01-2021

\begin{abstract}
Abstrak
Anak tunarungu mengalami keterbatasan dalam berbahasa dan komunikasi, sehingga guru disekolah luar biasa dituntut mempunyai strategi dalam menyampaikan materi matematika agar mereka dapat memahami materi dengan baik. Penggunaan media pembelajaran bagi anak tunarungu dapat memberikan pengaruh kepada anak tunarungu agar konsep-konsep dan ide matematika yang bersifat abstrak dapat dikaji, dipahami, dan dicapai oleh penalaran anak. Untuk itu penelitian ini bertujuan untuk menjelaskan kepraktisan media pembelajaran puzzle bangun datar segi empat pokok bahasan jajargenjang untuk anak tunarungu. Metode penelitian yang digunakan adalah pengembangan, menggunakan alur formative evaluation ditinjau dari tahap one-to-one dan small group. Subjek dalam penelitian ini adalah anak kelas VIII SLB-B Karya Ibu Palembang yang berjumlah 7 anak. Instrumen yang digunakan adalah angket, wawancara, observasi dan soal posstest . Dari hasil penelitian diperoleh simpulan bahwa:menghasilkan media pembelajaran puzzle bangun datar segi empat pokok bahasan jajargenjang yang praktis, kepraktisan media ini dilihat dari komentar dan saran anak pada tahap one-to-one dan small group. Kata Kunci: Anak tunarungu, media pembelajaran puzzle, pengembangan
\end{abstract}

\section{Learning Media for Puzzle Learning on Levels of Flat Building for Deaf Children}

\begin{abstract}
Deaf children experience limitations in language and communication, so teachers in special schools are required to have a strategy in conveying mathematics material so that they can understand the material well. The use of learning media for deaf children can have an influence on children with hearing impairment so that abstract mathematical concepts and ideas can be studied, understood, and achieved by children's reasoning. This study aimed to explain thepracticality of learning media fora flat rectangular puzzle. The research method used was development using a formative evaluation flow in terms of one-to-one and small group stages. The subjects in this study were 7 children in grade VIII SLB-B Karya Ibu Palembang. The instruments used were questionnaires, interviews, observation and posstest questions. From the results of the study, it was concluded that: producing learning media for a practical quadrilateral puzzle on the subject of practical jargar, the practicality of this media was seen from the comments and suggestions of children in the one-to-one and small group stages.
\end{abstract}

Keywords: Deaf children, puzzle learning media, development 


\section{Pendahuluan}

Pendidikan adalah hak setiap warga negara (Yuniawatika, dkk., 2016; Irfam Anzora, \& Fuadi, 2018; Sumartini, dkk., 2020). Sebagaimana diatur secara tegas dalam pasal 31 ayat (1) Undang-Undang Dasar 1945 yang menyatakan bahwa "setiap warga negara berhak mendapatkan pendidikan". Dalam pasal tersebut jelas dikatakan bahwa "setiap warga negara", ini berarti pemenuhan pendidikan tidak memandang status sosial termasuk anak berkebutuhan khusus.

Salah satu jenis anak berkebutuhan khusus adalah anak tunarungu. Tunarungu merupakan suatu keadaan kehilangan pendengaran yang mengakibatkan seseorang tidak dapat menangkap berbagai rangsangan terutama melalui indera pendengarannya (Somantri, 2018). Karena kehilangan pendengaran yang mengakibatkan anak kesulitan dalam mengikuti proses pembelajaran, tidak terkecuali dalam pelajaran matematika.

Matematika memiliki aturan serta bahasa yang terdefinisi, penalaran yang jelas dan sistematis antar konsepnya (Febrilia, 2019; Afriansyah, dkk., 2020). Selanjutnya Rahmi \& Musdi (2017), menyatakan bahwa matematika perlu diajarkan sejak dini karena memiliki peranan yang sangat penting diantaranya, membentukan pola pikir (Pitriani \& Afriansyah, 2016).

Berdasarkan fakta di lapangan, anak tunarungu mengalami kesulitan dalam memahami matematika yang berkaitan erat dengan geometri khususnya materi luas bangun datar jajargenjang. Mereka juga merasa bingung ketika bangun jajargenjang tersebut berubah posisi.

Bukti empiris dilapangan baik di Indonesia maupun di negara lain menunjukkan bahwa hasil pembelajaran geometri masih belum memuaskan (Molinasari \& Aryuna, 2017; Mulyo, Sari, \& Syarifuddin, 2019; Muslim \& Prabawati, 2020). Berdasarkan observasi yang telah dilakukan peneliti disalah satu sekolah, hal ini dikarenan proses pembelajaran yang biasa dilakukan oleh guru adalah menjelaskan secara langsung dengan bahasa oral yang sesekali diselingi dengan ilustrasi sebuah kertas untuk materi pengenalan bangun datar. Proses pembelajaran yang demikian membuat anak merasa bosan dan jenuh. Sebagaimana dinyatakan Komariah \& Sundayana (2017), munculnya kesulitan proses belajar matematika ditentukan juga dengan metode pembelajaran yang digunakan. Lebih lanjut, anak kurang terlibat dalam aktivitas belajar yang mengakibatkan mereka menjadi pasif dan bosan karena guru telalu banyak mendominasi.

Faktor lain yang mempengaruhi anak sulit memahami materi karena kurangnya kemampuan anak pada bahasa dan komunikasi (Afriansyah, 2015; Nuraeni, 2018; Dewi, Sundayana, \& Nuraeni, 2020; Rismen, Mardiyah, \& Puspita, 2020; Lestariningsih, Nurhayati, \& Cicinidia, 2020). Menurut Golos \& Mosos (2013), ketika mereka menempuh pendidikan formal, banyak anak tunarungu yang masih belajar 
bahasa. Kemudian anak tunarungu juga memiliki lebih sedikit kesempatan untuk belajar secara tidak sengaja sebagai akibat dari gangguan pendengaran mereka (Nunes \& Moreno, 2002).

Penggunaan media pembelajaran bagi anak tunarungu dapat menjadi salah satu alternatif bagi permasalahan di lapangan. Caryoto \& Meimulyani (2013), menyatakan bahwa anak tunarungu memiliki keterbatasan dalam mendengar dan berbicara sehingga media pembelajaran yang cocok untuk anak tunarungu adalah media visual dan cara menerangkannya dengan bahasa bibir atau gerak bibir. Hal ini selaras dengan pendapat Salim (2015), bahwa pengajaran pada anak tunarungu akan lebih efektif apabila objek pengajaran dapat divisualisasikan secara nyata menyerupai keadaaan sebenarnya.

Namun dalam sekolah tersebut ketersediaan media pembelajaran yang didesain sesuai anak tunarungu dan dapat memvisualisasikan proses pembelajaran sangat terbatas. Dengan bantuan media pembelajaran yang sesuai dapat memahami ide-ide dasar yang melandasi sebuah konsep, mengetahui cara membuktikan suatu rumus dan dapat menarik suatu kesimpulan dari hasil pengamatannya (Suwardi, Firmiana, \& Rohayati, 2016; Suwarsih, 2018; Nursyahidah, dkk., 2020; Lisnani \& Pranoto, 2020).

Salah satu media yang dapat digunakan dalam proses pembelajaran adalah puzzle. Kurniasih (2016) menyatakan bahwa puzzle adalah media yang dimainkan dengan cara bongkar pasang yang berfungsi untuk melatih ketelitian, koordinasi, logika, pengenalan konsep hubungan dan lain sebagainya. Penggunaan media pembelajaran puzzle juga dapat memotivasi anak dalam belajar, karena mereka bisa belajar sambil bermain.

Hasil penelitian yang dilakukan Silvia (2013), bahwa permainan puzzle tangkai efektif untuk mengenalkan bangun datar sederhana bagi anak tunarungu kelas II di SDLB N 20 Nan Balimo Kota Solok. Puzzle yang dimaksud dalam penelitian tersebut adalah puzzle yang bahannya berasal dari beberapa tangkai es krim dan dikombinasikan dengan gambar-gambar bangun datar pada tiap tangkainya. Puzzle tangkai digunakan sebatas pengenalan bentuk bangun datar sederhana persegi, persegi panjang, dan segitiga. Kemudian penelitian Sari (2012), pemanfaatan alat peraga yang berbentuk balok terdiri dari satuan puzzle, lampu benar salah dan tombol angka untuk memahami gagasan abstrak tentang persegi, persegi panjang, luas persegi dan luas persegi dapat meningkatkan pemahaman konsep mengenai luas bangun datar dan persegi panjang di atas $70 \%$.

Dengan demikian penggunaan media pembelajaran dapat memberikan pengaruh kepada anak tunarungu agar konsep-konsep dan ide dalam matematika yang sifatnya abstrak dapat dikaji, dipahami dan dicapai oleh penalaran anak, terutama anak yang masih memerlukan bantuan alat yang sifatnya nyata (Afriansyah, 2016). 
Dalam penelitian ini, peneliti mencoba mengembangkan media pembelajaran puzzle bangun datar yang didesain dan disesuaikan dengan kebutuhan serta karakteristik anak tunarungu. Materi yang dikembangkan adalah luas bangun datar segi empat pokok bahasan jajargenjang.

\section{Metode}

Metode penelitian yang digunakan adalah pengembangan, dengan menggunakan tahap prototyping alur desain formative evaluation yang dikemukakan oleh Tessmer (1993). Adapun subjek dalam penelitian adalah siswa kelas VIII Sekolah Luas Biasa Karya Ibu Palembang Tahun Pelajaran 2019 yang berjumlah 7 anak, dengan karakteristik 3 anak memiliki kemampuan tinggi, 2 anak kemampuan sedang dan 2 anak kemampuan rendah.

Berdasarkan identifikasi kurikulum pada tahap awal yang bertujuan untuk mengetahui lebih dalam mengenai susunan materi, cakupan materi, dan kedalaman materi pelajaran matematika, bahwasannya materi bangun datar diajarkan pada kelas VIII. Kemudian teknik pengumpulan data yang digunakan dalam penelitian ini adalah angket, wawancara, observasi. Dalam memenuhi kepraktisan, alur yang digunakan peneliti adalah formative evaluation yang ditinjau dari tahap one-to-one dan small group.

Setelah peneliti mengkaji hal apa saja yang mendukung dalam komponen pembuatannya, maka langkah selanjutnya adalah medesign media pembelajaran puzzle. Kerangka media pembelajaran puzzle yang didesain ada dua yaitu: 1) Papan alas, adalah papan yang dibuat untuk menempelkan puzzle bangun datar segi empat pokok bahasan jajargenjang dan belah ketupat. Bahan yang digunakan adalah tripleks, peneliti memotong menjadi bentuk persegi panjang berukuran $90 \mathrm{~cm} \times 60 \mathrm{~cm}$ dengan tebal 8 inc, kemudian keempat sisinya dilengkapi bingkai berwarna coklat berukuran $4 \mathrm{~cm}$.

Sebelum nemempelkan bingkai terlebih dahulu dilapisi seng. Penggunaan seng bertujuan agar puzzle menempel kuat pada papan alas. Kemudian peneliti mulai mendesign papan alas dengan tema batik nuansa warna biru dikombinasikan dengan warna putih dan abu-abu sebagai alas dan warna merah untuk warna batiknya. Proses pengerjaan pembuatan papan alas berlangsung sekitar satu minggu. 2) puzzle, dibentuk seperti dua jenis bangun datar yaitu persegi panjang, jajargenjang. Bangun ini dibuat menyerupai permaianan puzzle dengan cara memotongnya menjadi beberapa bagian.

Media pembelajaran puzzle ini memberikan aktivitas visual bagi siswa tunarungu, dimana mereka harus menyusun puzzle membentuk bangun datar segi empat jajargenjang serta membuat proses belajar menjadi menyenangkan karena anak bisa belajar sambil bermain. Fokus penelitian ini adalah menghasilkan media pembelajaran puzzle yang praktis, dengan melihat aspek kejelasan, lingkungan, minat penerimaan dan aspek persetual untuk tahap one-to-one 
dan aspek efektivitas pembelajaran, daya tarik dan daya implementasi dalam tahap small group.

\section{Hasil dan Pembahasan}

\section{A. Hasil Penelitian}

Setelah design dan rancangan awal media pembelajaran dinyatakan valid kemudian media tersebut diuji cobakan kepada anak tunarungu untuk melihat kepraktisan. Ada tiga siklus yang digunakan peneliti dalam melihat kepraktisan media pembelajaran puzzle, berikut uraiannya;

\section{Tahap One-To-One Menggunakan \\ Video Tutorial}

Karena terkendala untuk bisa bertatap muka, maka peneliti mencari alternatif dengan melakukan tahap one-to-one siklus pertama secara online. Peneliti membuat video tentang media pembelajaran puzzle, video berdurasi 4 menit 54 detik. Dalam video tersebut peneliti memperkenalkan bagian-bagian dari media pembelajaran puzzle serta menjelaskan lembar kerja siswa.

Pada tahap ini peserta didik merasa ada kesulitan melakukan pembelajaran menggunakan media pembelajaran puzzle. Kemudian berdasarkan hasil angket dan wawancara peserta didik masih kesulitan karena banyak langkah yang harus dicobakan serta banyak puzzle yang digunakan. Tidak terdapat perbaikan prototype 1 pada tahap ini.

\section{Tahap One-To-One menggunakan Media Ilustrasi.}

Berdasarkan analisis dari setiap aktivitas anak, mulai dari menguji cobakan media pembelajaran kepada dua orang anak dengan karakteristik satu anak kemampuan tinggi dan satu anak memiliki kemampuan rendah, dengan memberikan lembar kerja siswa, data lembar instrumen dan wawancara, anak merasa senang karena bisa menguji cobakan media puzzle walaupun hanya dengan media ilustrasi. Kemudian ada beberapa poin yang menjadi pertimbangan peneliti dalam merevisi media pembelajaran puzzle. Anak merasa bingung pada saat menyususn puzzle untuk membentuk bangun datar jajargenjang dan belah ketupat, mereka mencoba berulang kali agar puzzle bisa tersusun dengan tepat. Kemudian terkait aspek design penggunaan warna.

Komentar dan saran anak dijadikan acuhan dalam merevisi media pembelajaran. Hasil revisi pada bagian ini disebut prototype 2. Gambaran media pembelajaran bagian papan alas sebelum direvisi dapat dilihat di Gambar 1.

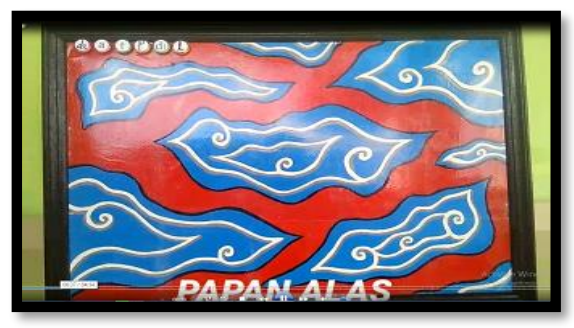

Gambar 1. Papan Alas Sebelum Revisi

Sebelum revisi papan alas bertema batik kalimantan dengan nuansa merah biru dikombinasikan warna putih. Kemudian untuk hasil revisi dapat dilihat pada Gambar 2. 


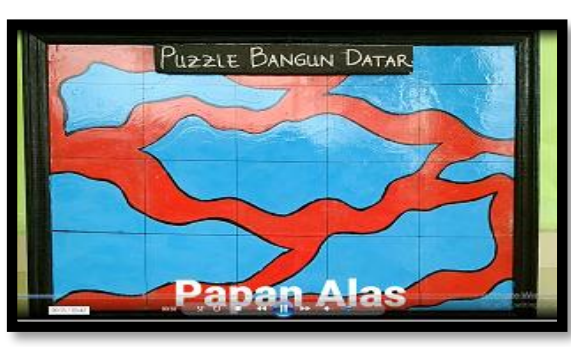

Gambar 2. Papan Alas Sesudah direvisi

Peneliti mengurangi warna pada papan alas, kemudian menambahkan nama "puzzle bangun datar" dan garis kotak satu-satuan.

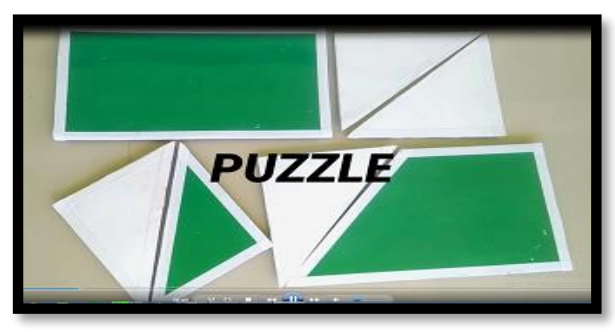

Gambar 3. Papan Alas Sebelum Revisi

Sebelum direvisi, puzzle dibuat menjadi 7 bagian dengan warna hijau dan putih. Seperti pada Gambar 3.

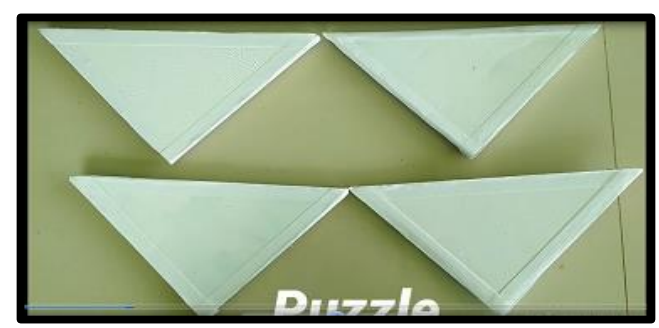

Gambar 4. Papan Alas Setelah Revisi

Pengurangan warna pada puzzle (lihat Gambar 4) bertujuan agar warna yang digunakan tidak berlebihan sehingga anak bisa terfokus pada materi. Kemudian peneliti memanfaatkan 4 bangun segitiga namun tetap menggunakan konsep bangun datar utama yaitu persegi panjang, karena anak memiliki kemampuan intelegensi yang berbeda dengan anak normal.

Penggunaan puzzle yang terlalu banyak akan membuat anak bingung. Jika melihat respon anak pada tahap one-one-one mereka bingung ketika dihadapkan dengan banyak langkah dan banyak puzzle.

\section{Small Group}

Media pembelajaran puzzle yang telah direvisi atau prototype 2 akan dievaluasi oleh anak berdasarkan aspek efektivitas pembelajaran, daya tarik, dan daya implementasi oleh 5 subjek dengan kategori 2 anak kemampuan tinggi, 2 anak kemampuan sedang dan satu anak kemampuan rendah.

Peneliti mengamati aktivitas anak dalam menguji cobakan media dengan hasil mereka berdiskusi dalam setiap langkahnya menggunakan bantuan lembar petunjuk dan video tutorial. Dalam proses diskusi ada yang lebih dominan dalam mengarahkan setiap langkah penggunaannya.

Berikut respon anak ketika memperagakan media pembelajaran puzzle.

Tabel 1.

Aktivitas Small Group

\begin{tabular}{|c|c|}
\hline Petunjuk & Respon \\
\hline $\begin{array}{l}\text { Tempelkan } \\
\text { bangun segitiga } \\
\text { padar kotak } \\
\text { papan alas }\end{array}$ & $\begin{array}{l}\text { Anak menempelkan satu } \\
\text { puzzle segitiga dengan } \\
\text { posisi bebas dan } \\
\text { mengabaikan garis-garis } \\
\text { bantu pada papan alas }\end{array}$ \\
\hline $\begin{array}{l}\text { Tentukan unsur } \\
\text { dari persegi }\end{array}$ & $\begin{array}{l}\text { Anak menempelkan pin } \mathrm{p} \\
\text { pada titik sudut dan pin } \\
\text { Idengan tepat. }\end{array}$ \\
\hline $\begin{array}{l}\text { Luas dari persegi } \\
\text { panjang } \\
\text { tersebut? }\end{array}$ & $p \times 1$ \\
\hline $\begin{array}{l}\text { Kemudian } \\
\text { pindahkan }\end{array}$ & $\begin{array}{l}\text { membongkar } \\
\text { dari bangun }\end{array}$ \\
\hline
\end{tabular}




\begin{tabular}{|c|c|}
\hline $\begin{array}{l}\text { bangun segitiga } \\
\text { tersebut, hingga } \\
\text { membentuk } \\
\text { bangun } \\
\text { jajargenjang. }\end{array}$ & $\begin{array}{lr}\text { persegi } & \text { panjang, } \\
\text { kemudian } & \text { mulai } \\
\text { membentuk } & \text { bangun } \\
\text { jajargenjang, } & \text { dengan } \\
\text { tepat. } & \text { Kemudian } \\
\text { menempelkan pin p pada } \\
\text { alas jajargenjang dan pin } \\
\text { I pada tinggi jajargenjang. }\end{array}$ \\
\hline $\begin{array}{l}\text { Dari percobaan di } \\
\text { atas, perhatikan } \\
\text { dari unsur } \\
\text { jajargejang. }\end{array}$ & $\begin{array}{l}\text { Panjang = alas } \\
\text { Lebar = tinggi. }\end{array}$ \\
\hline $\begin{array}{l}\text { Dengan } \\
\text { menurunkan } \\
\text { rumus luas } \\
\text { persegi panjang, } \\
\text { maka rumus luas } \\
\text { jajargenjang } \\
\text { adalah }\end{array}$ & alas $x$ tinggi \\
\hline
\end{tabular}

Jika dilihat respon kelima anak pada saat menguji cobakan media pembelajaran puzzle, menggunakan bantuan garis-garis kotak satu-satuan pada papan alas. Hanya ada satu anak yang menempelkan puzzle secara bebas. Dilanjutkan pada saat menguji coba mereka melihat video tutorial bersamaan petunjuk penggunaannya. Ketika anak bingung dalam langkah lembar kerja siswa maka peneliti nunjukan video lembar kerja siswa dan sesekali menjelaskan dengan bahasa bibir dan bahasa isyarat SIBI

Kemudian dari hasil wawancara yang telah dilakukan dapat disimpulkan bahwa $60 \%$ anak belum pernah menggunakan media pembelajaran puzzle, hanya 2 anak yang pernah menggunakan media media tersebut. Sedangkan dari segi materi pelajaran semua pernah belajar tentang rumus luas jajargenjang, namun sebagian dari mereka yang diingat adalah rumus luas persegi panjang.
Kemudian hasil instrumen menunjukan bahwa dari segi efektivitas pembelajaran semua anak menyatakan bahwa mereka dapat menggunakan media pembelajaran puzzle bangun datar segi empat dengan mudah dan belajar menggunakan media pembelajaran tersebut merupakan pengalaman yang berharga.

Menurut mereka guru dapat menggunakan media pembelajaran puzzlesebagai rancangan dalam proses pembelajarn menemukan rumus luas jajargenjang karena dinilai media pembelajaran tersebut mudah dipahami, dimengerti, dan mudah dilakukan.

Dari aspek daya tarik, lima siswa menyatakan senang belajar matematika menggunakan media pembelajaran puzzle bangun datar, menurut mereka selain mudah dipahami dan dimengerti serta bentuknya jelas mereka juga bisa belajar sambil bermain, bentuknya jelas dan menarik dan lebih ringkas. Untuk aspek daya implementasi, 4 anak menyatakan memiliki keterampilan dalam menggunakan media pembelajaran puzzle bangun datar segi empat.

Selain melakukan penilaian dengan lembar instrumen small group, peneliti juga memberikan 4 soal posttes terhadap kelima anak, dengan indikator soal menjelaskan sifat jajargenjang, menentukan luas daerah jika diketahui alas dan tinggi, menentukan tinggi jika diketahui luas dan alas dan menyelesaikan masalah yang berkaitan dengan menghitung luas jajargenjang. Soal posttest yang diberikan kepada anak 
sebelumnya di validasi oleh pakar. Dari soal posstest tersebut didapat semua siswa telah memenuhi standar KKM ( $\geq 75)$.

\section{B. Pembahasan}

Kepraktisan media pembelajaran didapat berdasarkan komentar dan saran anak pada setiap tahap one-to-one dan small group.Sebelum menjadi prototype 2, terdapat revisi yang telah dilakukan peneliti pada tahap one-to-one yang terfokus pada design. Yakni pengurangan penggunaan warna pada papan alas dan puzzle.

Pada tahap one-to-one melihat evaluasi dari sudut pandang pembelajar (Tessmer, 1993). Sama halnya dengan expert review, anak merasa kesulitan jika banyak menggunakan puzzle serta petunjuk yang banyak pula. Maka peneliti mencari alternatif dalam menurunkan rumus luas jajargenjangdengan menggunakan 4 puzzle bangun segitiga.

KemudianBerdasarkan data instrumen pada tahap one-to-one, anak tertarik dalam penggunaan media pembelajaran puzzle, belajar menggunakan media pembelajaran puzzle memberikan pengalaman yang baru dan juga media tersebut mudah digunakanoleh anak karena rumus dan bentuknya sudah jelas, walaupaun masih memerlukan bantuan dari peneliti maupun orangtua dikarenakan keterbatasan komunikasi.

Hasil ini sejalan dengan teori kepraktisan menurut Nieveen (2012), kepraktisan media yang dibuat mempertimbangkan kemudahan. Kemudahan yang dimaksud adalah media yang dibuat mudah untuk dipahami dan juga mudah untuk digunakan.

Kemudian pada tahap small group media dikatakan praktis dilihat dari aspek efektivitas pembelajaran yakni anak dapat menggunakan media pembelajaran puzzle dengan mudah, guru dapat menggunakan media pembelajaran puzzle sebagai rancangan dalam proses pembelajaran.

Sebagaimana pendapat Iklimah (2017), menyatakan bahwa kepraktisan dalam pengembangan media pembelajaran dapat diambil dari sisi penggunanya, dimana suatu media pembelajaran dikatakan praktis apabila media tersebut dapat dengan mudah digunakan sebagai pembelajaran, dalam hal ini respon siswa yang akan menjadi tolak ukur kepraktisan media yang dikembangkan.

Kemudian praktis dari aspek daya tarik, anak merasa senang dan tertarik belajar menggunakan media puzzle karena mereka bisa belajar sambil bermain, cepat dipelajari dan menarik. Sedangkan dari aspek implementasi belajar menggunakan media pembelajaran puzzle bangun datar segi empat tidak banyak menghabiskan waktu serta tidak merasa kesulitan dalam menggunakannya.

Dari aspek ini, media pembelajaran puzzle bangun datar segi empat membantu anak dalam mengenalkan materi geometri dengan cara visualisasi. Dalam pengajaran matematika penting untuk membuat konsep matematika lebih visual terutama anak tunarungu yang mengalami gangguan 
pendengaran yang mengakibatkan kesulitan berkomunikasi (Chen, 2006).

Media ini juga membantu anak menemukan rumus luas jajargenjang dan belah ketupat dengan mudah dengan bentuk dan cara menurunkan rumusnya jelas. Hal ini sejalan dengan penemuan Sari \& Hasibuan (2013), media pembelajaran puzzle mempunyai pengaruh yang signifikat antara pengguna media pembelajaran puzzle terhadap kemampuan anak dalam materi bangun datar

Media pembelajaran puzzle ini cocok untuk setiap tingkatan anak, mulai dari kemampuan cepat menangkap (tinggi), sedang, dan sulit menangkap (rendah), karena langkah penurunan rumus luas jajargenjang dan belah ketupat yang terurut dan sistematis serta disesuaikan dengan kondisi atau karakter anak yang mengalami kesulitan dalam berbahasa dan komunikasi.

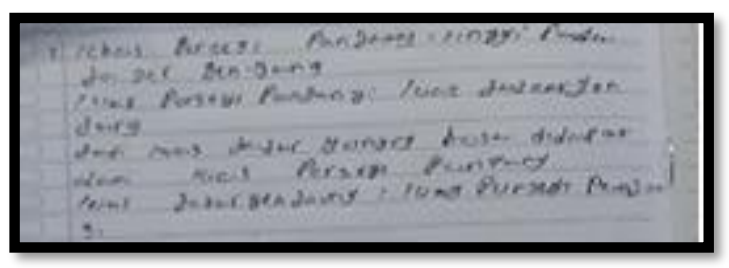

Gambar 5. Salah Satu Jawaban Anak Soal Posttest

Ketika anak diberikan soal posstest, ada subjek yang menulis bahwa rumus luas jajargenjang sama dengan rumus luas persegi panjang. Dengan mengetahui unsur-unsur dari persegi panjang, yaitu panjang sama saja dengan alas (lihat Gambar 5). Dan unsur lebar sama saja dengan tinggi pada bangun jajargenjang.

Hal ini bisa menjadi pengalaman belajar yang menarik bagi anak bahwa rumus jajargenjang dan belah ketupat adalah turunan dari rumus luas persegi panjang. Berdasarkan penjabaran diatas yang telah sesuai dengan hasil akhir yang diinginkan untuk mencapai kepraktisan, maka dapat disimpulkan bahwa media pembelajaran puzzle bangun datar segi empat pokok bahasan jajargenjang dan belah ketupat yang dikembangkan telah praktis.

\section{IV . Penutup}

Berdasarkan hasil penelitian dan pembahasan mengenai media Pembelajaran Puzzle pada Bangun Datar Jajargenjang untuk Anak Tunarungu dapat disimpulkan bahwa media pembelajaran puzzle bangun datar segi empat pokok bahasan jajargenjang dan belah ketupat yang telah dikembangkan tergolong praktis. Kepraktisan media ini berdasarkan komentar dan saran anak pada setiap tahap one-to-one dan small group yang dijadikan acuan untuk merevisi media pembelajaran puzzle.

Kemudian terdapat beberapa saran dari peneliti diantaranya yaitu bahan yang digunakan dalam membuat puzzle bisa menggunakan bahan lain atau bahan tripleks dengan ketebalan lebih dari $4 \mathrm{~mm}$ agar lebih tahan lama, dapat mendesign papan alas dengan tema yang lain agar lebih menarik perhatian anak, dan warna yang digunakan pada papan alas dapat divariasikan lagi. Selain itu, peneliti menyarankan untuk peneliti selanjutnya dapat membuat lembar kerja siswa menjadi 
modul kecil atau versi lain sehingga lebih praktis dan menarik.

\section{UCAPAN TERIMA KasIH}

Terimakasih kami sampaikan kepada seluruh civitas akademika UIN Raden Fatah Palembang dan SLB-B Karya Ibu, yang telah banyak membantu sehingga proses penelitian berjalan dengan baik.

\section{Daftar Pustaka}

Afriansyah, E. A. (2016). Enhancing Mathematical Problem Posing via Realistic Approach. International Seminar on Mathematics. Science, and Computer Science Education MSCEIS.

Afriansyah, E. A. (2015). Qualitative became easier with ATLAS. ti. In International Seminar on Mathematics, Science, and Computer Science Education MSCEIS.

Afriansyah, E. A., Herman, T., Turmudi, T., \& Dahlan, J. A. (2020). Mendesain Soal Berbasis Masalah untuk Kemampuan Berpikir Kritis Matematis Calon Guru. Mosharafa: Jurnal Pendidikan Matematika, 9(2), 239-250.

Caryoto dan Meimulyani, Y. (2013). Media Pembelajaran Adaptif. Jakarta: Luxima Metro Media.

Chen, K. (2006). Math in motion: Origami math for students who are deaf and hard of hearing. Journal of deaf studies and deaf education, 11(2), 262-266.

Dewi, R. S., Sundayana, R., \& Nuraeni, R. (2020). Perbedaan Peningkatan Kemampuan Komunikasi Matematis dan Self-Confidence antara Siswa yang
Mendapatkan DL dan PBL. Mosharafa: Jurnal Pendidikan Matematika, 9(3), 463-474.

Febrilia, B. R. A. (2019). Penalaran Statistis Siswa dalam Menyelesaikan Masalah Case Study. Mosharafa: Jurnal Pendidikan Matematika, 8(2), 179-190. Golos, D. B., \& Moses, A. M. (2013). Developing preschool deaf children's language and literacy learning from an educational media series. American Annals of the Deaf, 158(4), 411-425.

Iklimah, M. (2017). Pengembangan Media Pembelajaran Interaktif Dengan Menggunakan Software Construct 2 Pada Mata Pelajaran Elektronika Dasar Di Smk Negeri 1 Sidoarjo. Jurnal Pendidikan Teknik Elektro, 7(1), 125137.

Irfan, A., Anzora, A., \& Fuadi, T. M. (2018). Analisis Pedagogical Content Knowledge Mahasiswa Calon Guru Pada Program Studi Pendidikan Matematika. Mosharafa: Jurnal Pendidikan Matematika, 7(2), 239-250. Komariah, I., \& Sundayana, R. (2017). Meningkatkan Aktivitas Belajar Matematika Siswa dengan Menggunakan Media Domat. Mosharafa: Jurnal Pendidikan Matematika, 6(3), 323-332.

Lestariningsih, L., Nurhayati, E., \& Cicinidia, C. (2020). Jenis Proses Berpikir Peserta Didik dalam Menyelesaikan Soal Literasi Matematis. Mosharafa: Jurnal Pendidikan Matematika, 9(1), 83-94. 
Lisnani, L., \& Pranoto, Y. H. (2020). Peningkatan Pemahaman Konsep Bilangan Bulat Melalui Cerita Si Unyil Berbasis ICT. Mosharafa: Jurnal Pendidikan Matematika, 9(2), 215-226. Molinasari, N., Sujadi, I., \& Aryuna, D. R. (2017). Analisis Tingkat Berpikir Siswa Kelas Vii Semester II Smp Negeri 14 Surakarta dalam Memecahkan Masalah Geometri Berdasarkan Teori Van Hiele Pada Pokok Bahasan Bangun Datar Jajargenjang dan Belah Ketupat. Jurnal Pendidikan Matematika Dan Matematika Solusi, 1(6), 8-16.

Mulyo, M. R. G. T., Sari, A. F., \& Syarifuddin, A. (2019). Proses Berpikir Siswa Bergaya Kognitif Visualizer dalam Menyelesaikan Masalah TIMSS Non Geometri. Mosharafa: Jurnal Pendidikan Matematika, 8(1), 167-178. Muslim, S. R., \& Prabawati, M. N. (2020). Studi Etnomatematika terhadap Para Pengrajin Payung Geulis Tasikmalaya Jawa Barat. Mosharafa: Jurnal Pendidikan Matematika, 9(1), 59-70.

Nieveen, N., \& A.E. Kelly. (2012). An Introduction to Educational Design Research. Enschede: University of Twente

Nunes, T., \& Moreno, C. (2002). An intervention program for promoting deaf pupils achievement in mathematics. Journal of Deaf Studies and Deaf Education, 7(2), 120-133.

Nuraeni, R. (2018). Perbandingan Kemampuan Komunikasi Matematis Mahasiswa antara yang Mendapatkan
Pembelajaran Group Investigation Dengan Konvensional pada Mata Kuliah Kalkulus Integral. Mosharafa: Jurnal Pendidikan Matematika, 7(2), 219-228. Nursyahidah, F., Saputro, B. A., Albab, I. U., \& Aisyah, F. (2020). Pengembangan learning trajectory-based instruction materi kerucut menggunakan konteks megono gunungan. Mosharafa: Jurnal Pendidikan Matematika, 9(1), 47-58.

Pitriani, R., \& Afriansyah, E. A. (2016). Persepsi dalam pembelajaran pendekatan keterampilan proses terhadap kemampuan koneksi matematis siswa (Studi penelitian di SMP Negeri 1 Wanraja). Jurnal Gantang, 1(2), 15-24.

Rahmi, M., Yerizo, Y., \& Musdi, E. (2017). Tahap Preliminary Research Pengembangan Perangkat Pembelajaran Berbasis Penemuan Terbimbing untuk Meningkatkan Kemampuan Komunikasi Matematis Peserta Didik Kelas VIII Mts/SMP. Mosharafa: Jurnal Pendidikan Matematika, 6(2), 237-246.

Rismen, S., Mardiyah, A., \& Puspita, E. M. (2020). Analisis Kemampuan Penalaran dan Komunikasi Matematis Siswa. Mosharafa: Jurnal Pendidikan Matematika, 9(2), 263-274.

Salim, A. (2015). Pembelajaran Matematika Berbasis Komputer Dengan Metode Multikomunikasi Untuk Siswa Kelas IV SDLB Penyandang Tuna Rungu Dan Wicara. Jurnal Techno Nusa Mandiri, 12(1), 77-95. 
Sari, A. P. K., \& Hasibuan, R. (201). Pengaruh Media Puzzle Terhadap Kemampuan Anak Mengenal Bentuk Geometri Kelompok A di TK Aneka Ria.

Sari, D. M. (2010). Penggunaan Puzzle Light Pada Pembelajaran Matematika Pokok Bahasan Luas Persegi dan Persegi Panjang Di Sekolah Luar Biasa-B Karnnamanohara, Yogyakarta.

Silvia, A., Martias, Z., \& Hasan, Y. (2013). Efektivitas Permainan Puzzle Tangkai untuk Mengenalkan Bangun Datar Sederhana Bagi Anak Tunarungu Kelas II B. Jurnal Penelitian Pendidikan Khusus, 2(3), 1-16.

Somantri, Sutjihati. (2018). Psikologi Anak Luar Biasa. Bandung: Refika Aditama.

Sumartini, T. S., Sunday, R., Madio, S. S., Afriansyah, E. A., Puspitasasri, N., Nuraeni, R., \& Lurytawati, I. P. (2020). Pedagogical Content Knowledge. Jurnal Pekemas, 3(1), 10-12.

Suwardi, S., Firmiana, M. E., \& Rohayati, R. (2016). Pengaruh Penggunaan Alat Peraga terhadap Hasil Pembelajaran Matematika pada Anak Usia Dini. Jurnal Al-Azhar Indonesia Seri Humaniora, 2(4), 297-305.

Suwarsih, S. (2018). Meningkatkan Hasil Belajar Siswa tentang Perkalian dan Pembagian Bilangan Cacah melalui Alat Peraga. Mosharafa: Jurnal Pendidikan Matematika, 7(3), 433-444.

Tessmer, M. (1993). Merencanakan dan Melakukan Evaluasi Formatif. London: Kogan Page.
Yuniawatika, Y., Yuspriyati, D. N., Sani, I., \& Febriyanti, F. (2016). Perkembangan Pendidikan Matematika Realistik Indonesia (PMRI) di LPTK Bandung Raya. Mosharafa: Jurnal Pendidikan Matematika, 5(3), 233-246.

\section{Riwayat Hidup PenUlis Vina Septiyani, S.Pd.}

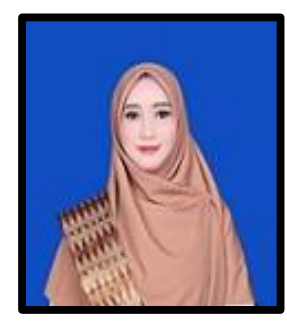

Lahir di OKU Timur, 01 September 1998. Studi S1 Pendidikan Matematika Universitas Islam Negeri Raden Fatah Palembang, lulus tahun 2020.

\section{Dr. Hartatiana, M.Pd.}

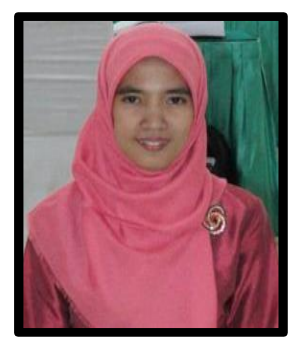

Lahir di Kayu Agung 03 Januari 1983. Staf pengajar di Pendidikan Matematika Uniiversitas Islam Negeri Raden Fatah Palembang. Studi S1 Pendidikan Matematika Universitas Sriwijaya Palembang, lulus tahun 2006; S2 Pendidikan Matematika Universitas Sriwijaya Palembang, lulus tahun 2010; S3 Pendidikan Matematika Universitas Pendidikan Indonesia Bandung, lulus tahun 2017.

\section{Ambarsari Kusuma Wardani, M.Pd,}

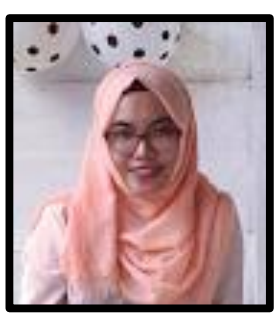

Lahir di Palembang 29 Desember 1989. Studi S1 Pendidikan Matematika Universitas Sriwijaya Palembang, lulus tahun 2011; S2 Pendidikan Matematika Universitas Sriwijaya Palembang, lulus tahun 2014. 